Marquette University

e-Publications@Marquette

5-1-1999

\title{
Thermal Decomposition and Combustion of $\gamma$ - irradiated Polyamide 6 Containing Phosphorus Oxynitride or Phospham
}

\author{
A. I. Balabanovich \\ Belarussian State University \\ Sergei V. Levchik \\ Belorussian State University \\ Galina F. Levchik \\ Belorussian State University \\ W. Schnabel \\ Bereich Physikalische Chemie \\ Charles Wilkie \\ Marquette University, charles.wilkie@marquette.edu
}

Accepted version. Polymer Degradation and Stability, Vol. 64, No. 2 (May 1999): 191-195. DOI. (C) 1999 Elsevier B.V. Used with permission. 


\section{Marquette University \\ e-Publications@Marquette}

\section{Chemistry Faculty Research and Publications/College of Arts and Sciences}

This paper is NOT THE PUBLISHED VERSION; but the author's final, peer-reviewed manuscript. The published version may be accessed by following the link in the citation below.

Polymer Degradation and Stability, Vol. 64, No. 2 (May, 1999): 191-195. DOI. This article is (c) Elsevier and permission has been granted for this version to appear in $\underline{\mathrm{e}-}$

Publications@Marquette. Elsevier does not grant permission for this article to be further copied/distributed or hosted elsewhere without the express permission from Elsevier.

\section{Thermal Decomposition and Combustion of $y$-irradiated Polyamide 6 Containing Phosphorus Oxynitride or Phospham}

\section{A.I. Balabanovich}

Research Institute for Physical Chemical Problems, Belarussian State University, Leningradskaya, Minsk, Belarus

S.V. Levchik

Research Institute for Physical Chemical Problems, Belarussian State University, Leningradskaya, Minsk, Belarus

G.F. Levchik

Research Institute for Physical Chemical Problems, Belarussian State University, Leningradskaya, Minsk, Belarus W. Schnabel 
Hahn-Meitner-Institut Berlin GmbH, Bereich Physikalische Chemie, Berlin, Germany

C.A.Wilkie

Department of Chemistry, Marquette University, Milwaukee, WI

\section{Abstract}

Polyamide 6 (PA-6) containing the fire retardants phosphorus oxynitride $\left((\mathrm{PON})_{\mathrm{m}}\right)$ or phospham $\left(\left(\mathrm{PN}_{2} \mathrm{H}\right)_{n}\right)$ was exposed to ${ }^{60} \mathrm{Co}-\mathrm{y}$-rays (absorbed dose: 1.0-4.0 MGy). The irradiation led to crosslinking of the polymer which caused an increase in the char yield and a decrease in the flammability of the polymer. The combustion behavior was strongly affected by irradiation: dripping was totally prevented in the case of system PA-6/(PN $\left.{ }_{2} \mathrm{H}\right)_{n}$ and strongly retarded in the case of system PA-6/(PON $)_{m}$. The thermal stability of the system PA-6/(PN $\left.2 \mathrm{H}\right)_{n}$ decreased with increasing absorbed dose whereas the thermal stability of the system PA$6 /(\mathrm{PON})_{m}$ did not change.

\section{Introduction}

In our earlier work ${ }^{[1]}$ we studied the influence of high energy irradiation on the thermal stability of polyamide 6 . It was shown that irradiated polyamide shows volatilisation at lower temperature than the unirradiated polymer because of the presence of low molecular weight material generated by radiation-induced chain scission. Apart from chain scission, irradiation also produces intermolecular cross-links and this leads to increased char formation when the irradiated polyamide is heated to $600^{\circ} \mathrm{C}$. However, in contrast to the expectation, in this case the enhancement in the char yield is not connected to a decrease in the flammability of the polymer. This might be due to the fact that the amount of char is not high enough to cause fire retardancy ${ }^{[2]}$. Generally, an increase in the char yield is attainable with the aid of crosslinkingaccelerating additives. For example, it was shown ${ }^{[1]}$ that phospham, a phosphorus nitrogen polymer, accelerates radiation-induced crosslinking of polyamide 6 more efficiently than triallylcyanurate, a commercial crosslinking enhancer, and that polyamide 6 crosslinked by ${ }^{60} \mathrm{Co}-\gamma$-rays and containing phospham exhibited relatively extensive charring ${ }^{[1]}$.

In this work, new results concerning the influence of ${ }^{60} \mathrm{Co}-\mathrm{y}$-irradiation on the charring and combustion performance of polyamide 6 containing phospham or phosphorus oxynitride are presented. These compounds are known to be effective fire retardants for aliphatic polyamides $3, \underline{4}$.

\section{Experimental part}

A commercial polyamide 6 (PA-6, product of Khimvolokno, Grodno, $M_{n}=3.5 \times 10^{4} \mathrm{~g} \mathrm{~mol}^{-1}$ ) was used. 


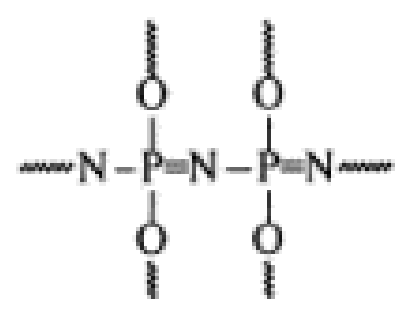

Phosphorus oxynitride $(\mathrm{PON})_{m}$ of the hypothetical structure

was prepared according to the method suggested by Sommer ${ }^{[5]}$. Urea, melamine and phosphoric acid (85\% water solution) were mixed at the ratio $30: 1: 8$ and heated in an oven for $1 \mathrm{~h}$ at $120^{\circ} \mathrm{C}$ and then for $1.5-2.0 \mathrm{~h}$ at $350^{\circ} \mathrm{C}$. The cooled white mass was finely powdered and heated again in a stream of dried air at $750^{\circ} \mathrm{C}$ for $2 \mathrm{~h}$.

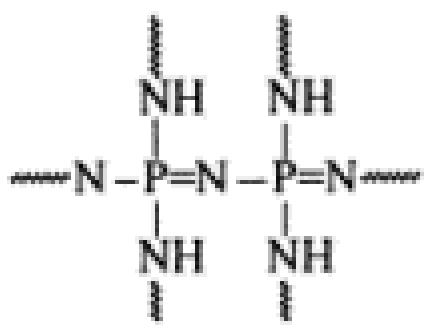

The imide analog of $(\mathrm{PON})_{m}$, phospham $(\mathrm{PN} 2 \mathrm{H})_{n}$ was prepared by heating in vacuum at $300^{\circ} \mathrm{C}$ for 2.0-3.0 h of hexaaminotricyclophospazene ${ }^{[6]}$.

PA-6 was mixed at a $20 \%$ wt level with $\left(\mathrm{PN}_{2} \mathrm{H}\right)_{n}$ or $(\mathrm{PON})_{m}$ in a closed mixer operated for 5 min at $60 \mathrm{rpm}$ at $240^{\circ} \mathrm{C}$. Bar specimens $(6 \times 3 \times 120 \mathrm{~mm})$ for combustion tests were cut from slabs prepared by compression molding at $250^{\circ} \mathrm{C}$. The specimens were irradiated under argon with ${ }^{60} \mathrm{Co}-\mathrm{\gamma}$-rays at an absorbed dose rate $D$ rabs $=2.6 \mathrm{kGy} / \mathrm{h}$.

Combustion tests were performed according to the ASTM D 2863 standard limited oxygen index (LOI) test. In this test the lowest limit of oxygen concentration in nitrogen/oxygen mixtures capable of sustaining candle-like combustion of vertically positioned polymer specimens is determined ${ }^{[7]}$. The samples were burned from the top and the char formed on top of the self-extinguished specimens was separated and weighted ( $\left.W_{\text {char }}\right)$. The char yield was then obtained according to Eq. (1)

\section{Char Yield $(\%)=\mathrm{w}_{\text {char }} /\left(\mathrm{w}_{\text {inr }}-\mathrm{w}_{\text {resid. }}\right)$.}

Here, $w_{\text {inr }}$ and $w_{\text {resid. }}$ denote the sample weight before and after burning, respectively. Horizontally positioned specimens were ignited in air to check the tendency of the samples to produce flaming drips. Thermal analysis was carried out under a flow of nitrogen or air (60 $\mathrm{cm}^{3} / \mathrm{min}$ ) at a heating rate $10^{\circ} \mathrm{C} / \mathrm{min}$ by using a Mettler thermal analyzer TA 3000 . 


\section{Results and discussion}

(a) Solubility tests: Irradiated samples containing either $\left(\mathrm{PN}_{2} \mathrm{H}\right)_{n}$ or $(\mathrm{PON})_{m}$ are insoluble in sulfuric acid even at the lowest absorbed dose (1.0 MGy), which indicates that the polymer is efficiently intermolecularly crosslinked upon irradiation with ${ }^{60} \mathrm{Co}-\mathrm{y}$-rays.

(b) Combustion tests: It is seen from Table 1 that in the case of system PA-6/(PN $2 \mathrm{H})_{n}$ the LOI grows from 29 for the unirradiated formulation to 33 for the formulation exposed to $3.0 \mathrm{MGy}$. Prolonged irradiation to $4.0 \mathrm{MGy}$ causes a decrease to $\mathrm{LOI}=32$.

Table 1. Effect of absorbed dose on limiting oxygen index and char yield

\begin{tabular}{|llll|}
\hline Additive & Absorbed dose (MGy) & LOI & Char yield (\%) \\
& 0 & 29 & 22 \\
$\left(\mathrm{PN}_{2} \mathrm{H}\right)_{n}$ & 2.5 & 32 & \\
& 3.0 & 33 & 25 \\
& 4.0 & 32 & 27 \\
& 0 & 28 & 33 \\
& 1.0 & 27 & 29 \\
$(\mathrm{PON})_{m}$ & 2.0 & 31 & 34 \\
& 3.0 & 31 & 44 \\
& 4.0 & 33 & 40 \\
\hline
\end{tabular}

In the case of system PA-6/(PON $)_{m}$ the LOI decreases at low irradiation dose (1.0 MGy) but increases at higher doses and reaches $\mathrm{LOI}=33$ at $4.0 \mathrm{MGy}$ which is definitely higher than $\mathrm{LOI}=28$ found for the unirradiated sample. From these results it is concluded that the fire retardancy of both systems is increased by irradiation with ${ }^{60} \mathrm{Co}-\gamma$-rays.

Both systems, PA-6/(PN $2 \mathrm{H})_{n}$ and PA-6/(PON $)_{m}$ exhibit a tendency to produce more char with increasing absorbed dose. This trend seems to be interrupted in the case of system PA$6 /(\mathrm{PON})_{m}$ at $D_{\mathrm{abs}}=1 \mathrm{MGy}$, where the char yield is lower than for the unirradiated sample.

Upon combustion in air unirradiated samples of both systems formed flaming drips but selfextinguished in the case of $\left(\mathrm{PN}_{2} \mathrm{H}\right)_{n}$ within $10 \mathrm{~s}$ and in the case of $(\mathrm{PON})_{m}$ within $30 \mathrm{~s}$. When irradiated samples were tested, it turned out that they also self-extinguished within 10 and 30 $\mathrm{s}$, respectively but flaming drips were not formed at all in the case of system PA-6/(PN $\left.{ }_{2} \mathrm{H}\right)_{n}$ and in the case of system PA-6/(PON $)_{m}$ flaming drips were formed with a rate reduced by the factor 5 compared to the unirradiated sample. Obviously, radiation-induced crosslinking totally prevents dripping during combustion in the case of $\left(\mathrm{PN}_{2} \mathrm{H}\right)_{n}$, and it retards dripping significantly in the case of $(\mathrm{PON})_{m}$.

(c) Thermal gravimetric analysis: TGA curves recorded with unirradiated and irradiated samples of system PA-6/(PN $\left.{ }_{2} \mathrm{H}\right)_{n}$ under argon or air are shown in Fig. 1 and Fig. 2, 
respectively. Analogous results obtained with the system PA-6/(PON) $m$ are shown in Fig. 3 and Fig. 4. The temperatures corresponding to $5 \%$ and $10 \%$ weight loss and the solid residue fractions measured at $450^{\circ} \mathrm{C}$ and $600^{\circ} \mathrm{C}$ are compiled in Table 2.

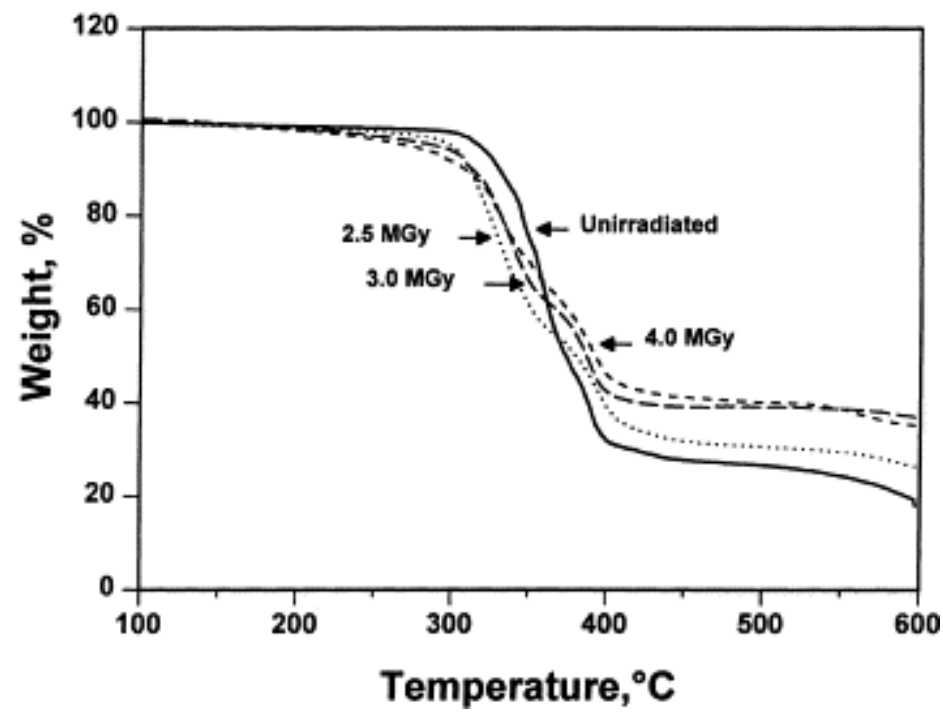

Fig. 1. Thermogravimetry of polyamide 6 containing $20 \mathrm{wt} \%\left(\mathrm{PN} \mathrm{N}_{2} \mathrm{H}\right)_{n}$ under argon. Curves of the unirradiated sample and of samples irradiated to different absorbed doses. Heating rate: $10^{\circ} \mathrm{C} / \mathrm{min}$, argon flow rate: $60 \mathrm{~cm}^{3} / \mathrm{min}$.

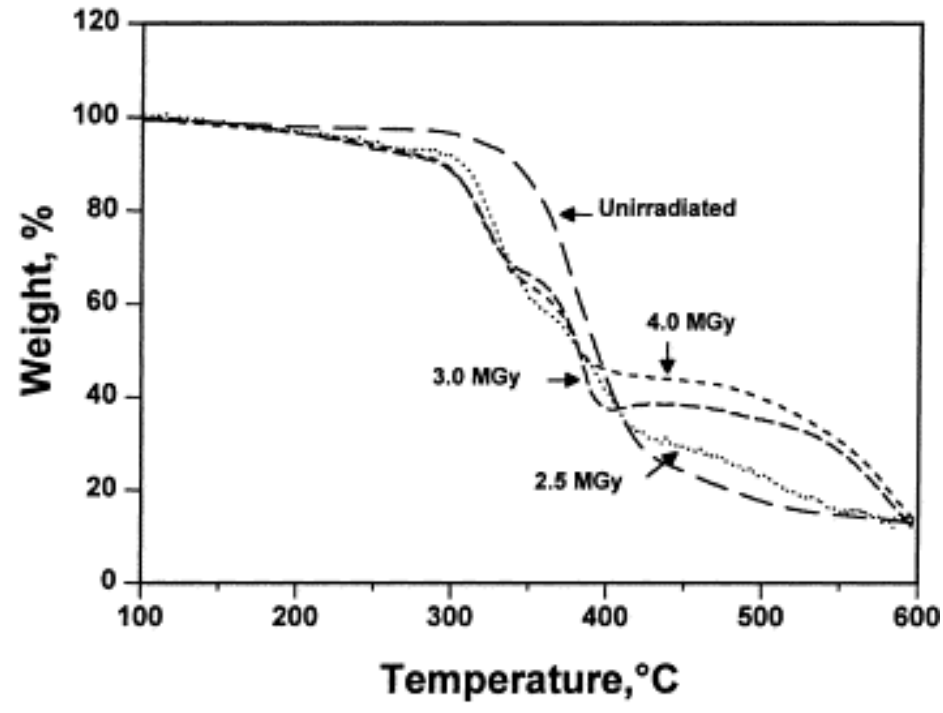

Fig. 2. Thermogravimetry of polyamide 6 containing $20 \mathrm{wt} \%\left(\mathrm{PN}_{2} \mathrm{H}\right)_{n}$ under air. Curves of the unirradiated sample and of samples irradiated to different absorbed doses. Heating rate: $10^{\circ} \mathrm{C} / \mathrm{min}$, air flow rate: $60 \mathrm{~cm}^{3} / \mathrm{min}$. 


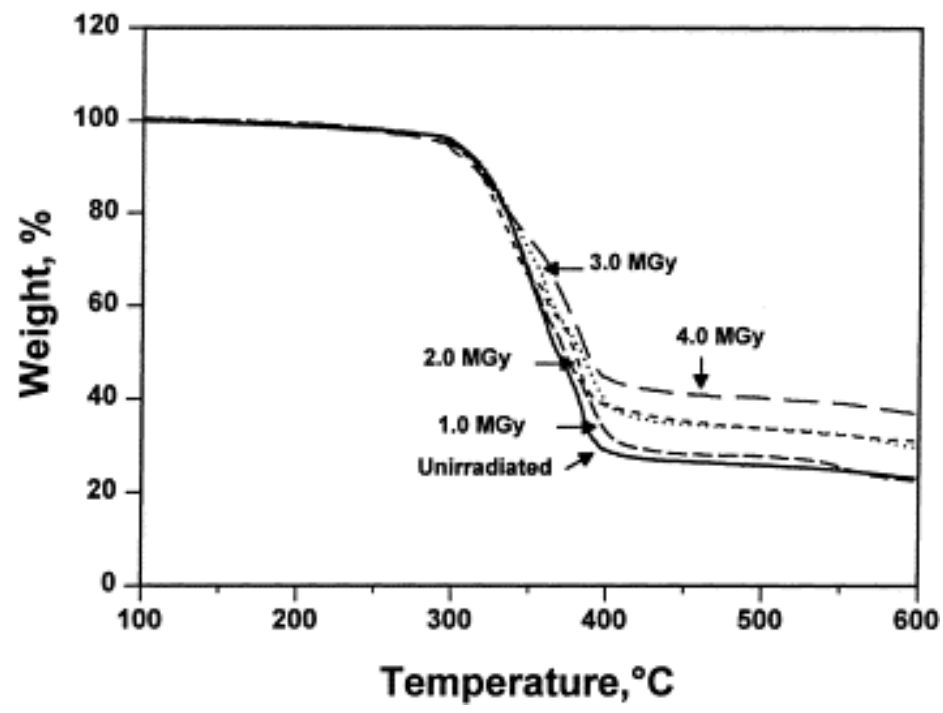

Fig. 3. Thermogravimetry of polyamide 6 containing $20 \mathrm{wt} \%(\mathrm{PON})_{m}$ under argon. Curves of the unirradiated sample and of samples irradiated to different absorbed doses. Heating rate: $10^{\circ} \mathrm{C} / \mathrm{min}$, argon flow rate: $60 \mathrm{~cm}^{3} / \mathrm{min}$.

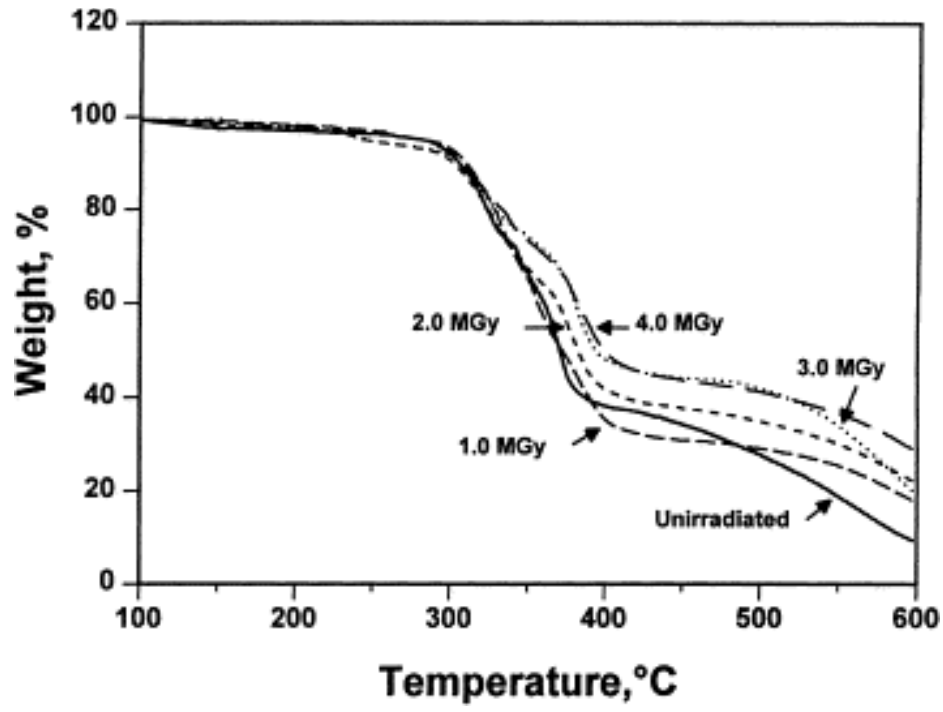

Fig. 4. Thermogravimetry of polyamide 6 containing $20 \mathrm{wt} \%(\mathrm{PON})_{m}$ under air. Curves of the unirradiated sample and of samples irradiated to different absorbed doses. Heating rate: $10^{\circ} \mathrm{C} / \mathrm{min}$, air flow rate: $60 \mathrm{~cm}^{3} / \mathrm{min}$. 
Table 2. Temperatures for $5 \%$ and $10 \%$ weight loss and amount of solid residue at $450^{\circ} \mathrm{C}$ and $600^{\circ} \mathrm{C}$

\begin{tabular}{|c|c|c|c|c|c|}
\hline \multicolumn{4}{|c|}{ Atmosphere in TGA Absorbed dose, MGy Temperature, ${ }^{\circ} \mathrm{C}$} & \multicolumn{2}{|c|}{ Solid residue, wt \% } \\
\hline & & $5 \%$ & $10 \%$ & $450^{\circ} \mathrm{C}$ & $600^{\circ} \mathrm{C}$ \\
\hline \multicolumn{6}{|c|}{$\left(\mathrm{PN}_{2} \mathrm{H}\right)_{n}$} \\
\hline \multirow[t]{4}{*}{ Argon } & 0 & 317 & 329 & 28 & 18 \\
\hline & 2.5 & 297 & 310 & 32 & 26 \\
\hline & 3.0 & 288 & 312 & 39 & 37 \\
\hline & 4.0 & 270 & 307 & 41 & 35 \\
\hline \multirow[t]{4}{*}{ Air } & 0 & 314 & 340 & 24 & 13 \\
\hline & 2.5 & 240 & 305 & 30 & 13 \\
\hline & 3.0 & 226 & 291 & 48 & 12 \\
\hline & 4.0 & 235 & 293 & 43 & 14 \\
\hline \multicolumn{6}{|c|}{$(\mathrm{PON})_{m}$} \\
\hline \multirow[t]{5}{*}{ Argon } & 0 & 301 & 318 & 26 & 18 \\
\hline & 1.0 & 298 & 315 & 28 & 23 \\
\hline & 2.0 & 296 & 314 & 35 & 31 \\
\hline & 3.0 & 299 & 318 & 36 & 30 \\
\hline & 4.0 & 294 & 312 & 41 & 37 \\
\hline \multirow[t]{5}{*}{ Air } & 0 & 281 & 304 & 34 & 9 \\
\hline & 1.0 & 281 & 306 & 31 & 18 \\
\hline & 2.0 & 244 & 301 & 37 & 22 \\
\hline & 3.0 & 243 & 304 & 42 & 20 \\
\hline & 4.0 & 280 & 306 & 42 & 29 \\
\hline
\end{tabular}

Irradiation destabilizes the system PA-6/(PN $2 \mathrm{H})_{n}$ as can be seen from Fig. 1 and Fig. 2. The $5 \%$ weight loss temperature is lowered as the absorbed dose increases. But the $10 \%$ weight loss temperature is only slightly influenced by the irradiation. The curve pertaining to the unirradiated sample of system PA-6/(PN $2 \mathrm{H})_{n}$ shows several steps in the thermal decomposition under argon (Fig. 1) but only one step in air (Fig. 2). The degradation curves of the irradiated samples give clear indication of the occurrence of two distinct degradation processes.

In the case of the system PA-6/(PON) $m$, tested both under argon (Fig. 3) and in air (Fig. 4), the onset of weight loss is not or only slightly affected by the irradiation. In fact, the temperatures of $5 \%$ weight loss (except at 2.0 and $3.0 \mathrm{MGy}$ ) and of $10 \%$ weight loss scatter insignificantly around constant values (Table 2). The unirradiated sample shows a two-step thermal decomposition pattern and the separation of the steps increases with increasing absorbed dose. 
In the cases of both systems, $\mathrm{PA}-6 /(\mathrm{PN} 2 \mathrm{H})_{n}$ and $\mathrm{PA}-6 /(\mathrm{PON})_{m}$, the solid residue fraction formed at $450^{\circ} \mathrm{C}$ both under argon and in air increases with increasing absorbed dose as can be seen from Fig. 1, Fig. 2, Fig. 3, Fig. 4 and Table 2. The same trend holds for the solid residue fraction formed at $600^{\circ} \mathrm{C}$ with one exception: in the case of system PA-6/(PN $\left.2 \mathrm{H}\right)_{n}$ the solid residue fraction formed in air does not depend on the absorbed dose. It seems that in the latter case the obtained residue is not resistant towards oxidation at the higher temperature which contrasts the situation met with system PA-6/(PON $)_{m}$. Here, the solid residue fraction formed in air at $600^{\circ} \mathrm{C}$ increases by a factor of about three when the absorbed dose grows from zero to 4 MGy. This indicates that in the case of system PA-6/(PON $)_{m}$ irradiation provides significant resistance of the solid residue towards oxidation.

In this connection it is interesting to compare these results with the combustion char yields (see Table 1). This comparison shows that the combustion char yield of system PA-6/(PN $2 \mathrm{H})_{n}$ is lower than that of system PA-6/(PON $)_{m}$ and the solid residue formed in air at $600^{\circ} \mathrm{C}$ of system PA-6/(PN $2 \mathrm{H})_{n}$ is also lower than that of system PA-6/(PON $)_{m}$. Therefore, in agreement

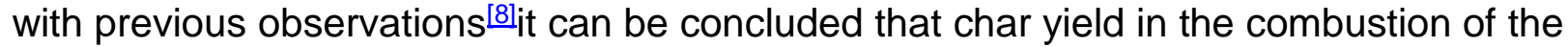
polymer depends on the thermal oxidation resistance of the char.

\section{Conclusions}

${ }^{60} \mathrm{Co}-\mathrm{y}$-rays induce crosslinking in polyamide 6 containing either phospham $\left(\left(\mathrm{PN}_{2} \mathrm{H}\right)_{n}\right)$ or phosphorus oxynitride $((\mathrm{PON}) \mathrm{m})$. Thermal gravimetric analysis revealed that the thermal stability of the system PA-6 $\left(\mathrm{PN}_{2} \mathrm{H}\right)_{n}$ decreases with increasing absorbed dose whereas it is not affected in the case of system PA-6/(PON $)_{m}$. A significant radiation-induced increase in the solid residue fraction, measured by thermogravimetry, and in the char yield determined in combustion tests, was observed with both systems, which is likely to be related to radiationinduced intermolecular crosslinking of the polyamide 6 .

In the case of system PA-6/(PON $)_{m}^{60} \mathrm{Co}-\mathrm{y}$-ray induced crosslinking provides significant resistance of the solid residue towards oxidation which does not apply to the system PA$6 /\left(\mathrm{PN}_{2} \mathrm{H}\right)_{n}$. This gives reason to assume that the protective action of the char layer formed during combustion does not only depend on its thickness but probably also on its "quality".

\section{Acknowledgements}

This work has been financially supported in part by the NATO Linkage grant OUTR.LG960310 and in part by a grant of the Fund of Fundamental Researches of Belarus.

\section{References}

1 Balabanovich AI, Levchik GF, Levchik SV, Schnabel W, Wilkie CA. Fire retardancy of polymers; the use of intumesence. In: Le Bras M, Camino G, Bourbigot S, Delobel R, editors. London: The Royal Society of Chemistry, 1998. p. 236.

2 Levchik SV, Wilkie CA. Fire retardancy of polymeric materials. In: Grand AF, Wilkie CA. editors, New York: Marcel Dekker (submitted).

3 Weil ED, Patel NG. Fire Mater. 1994;18:1 
4 Levchik SV, Levchik GF, Balabanovich AI, Weil ED, Klatt M. Angew Chemie (in press) 5 Sommer K. (to Benckiser-Knapsack). Br Pat 1975;1461:615

6 Miller TN, Vitola AA. Inorganic phosphorus and nitrogen compounds. Zinatne: Riga, 1986;Ch. 8 (In Russian)

7 Troitzsch J. International plastics flammability handbook, 2nd edition. Munich: Hanser

Publishers, 1990

8 Levchik SV, Camino G, Luda MP, Costa L, Muller G, Costes B, Henry Y. Polym for Adv Technol 1996;7:823 